\title{
Ultrastructure of cephalic appendage setae of marine planktonic copepods
}

\author{
G.-A. Paffenhöfer*, P. A. Loyd \\ Skidaway Institute of Oceanography, 10 Ocean Science Circle, Savannah, Georgia 31411, USA
}

\begin{abstract}
Our study aimed at determining which types of sensors are associated with setae on the cephalic appendages of marine calanoid copepods that create feeding currents. Such sensors enable copepods to rapidly identify potential food particles in the ambient water current, probably through chemical or hydrodynamic signals from the particles. We examined 4 copepod species, Centropages velificatus, Eucalanus pileatus, Paracalanus aculeatus and Temora stylifera, by scanning (SEM) and transmission (TEM) electron microscopy. Copepodids and adult females of all 4 species bear apical pores on the setae of their maxillipeds and second antennae, indicating potential chemoperceptive capabilities. TEM revealed putative chemo- and mechanosensors on the mandibular palp of C. velificatus and the second antennae of T. stylifera, supporting an earlier, similar report of sensors on the maxilliped of $T$. stylifera. As the setae of these 3 appendages are in almost continuous motion, at frequencies between $25 \mathrm{~Hz}$ (female E. pileatus) and $80 \mathrm{~Hz}$ (female P. aculeatus), food particles beyond the reach of the setae are believed to be recognised chemically by the apical pores of the individual setae. The observed mechanosensors are presumably used when handling larger food particles, as already described for T. stylifera during capture and alignment of elongated cells prior to ingestion.
\end{abstract}

KEY WORDS: Ultrastructure $\cdot$ Setae $\cdot$ Cephalic appendage $\cdot$ Marine planktonic copepods

\section{INTRODUCTION}

In an environment where food is only occasionally abundant, and usually scarce, the ability to exist is governed by being able to detect food organisms while at the same time limiting encounters with predators. Neritic regions of the oceans are such environments. Here, planktonic copepods have persisted using various means of overcoming disadvantageous conditions. These means include extreme adaptations, such as producing dormant eggs, but also extraordinary flexibility in obtaining sufficient food for maintenance, and even for some reproduction, at low food concentrations. For example, at the low concentration of $8 \mu \mathrm{g} \mathrm{Cl}^{-1}$ of the diatom Thalassiosira weissflogii ( 11 $\mu \mathrm{m}$ width), a copepodid Stage II of Eucalanus pileatus is able to ingest $78 \%$ of the amount which it ingested at $80 \mu \mathrm{g} \mathrm{C} \mathrm{l}^{-1}$ of the same food particle. This was attributed to its ability to increase the sensitivity of perceiving food particles at

*E-mail: cmp@skio.peachnet.edu a distance (Paffenhöfer \& Lewis 1990). There has been speculation on, and some attempts at documenting, the processes leading to the perception and eventual capture of such scarce food particles. First of all, the feeding current, which is created by copepodid stages and adults of numerous calanoid species, increases the frequency of encounter with food particles (e.g. Strickler 1984, 1985). Secondly, model calculations suggest that a combination of feeding current and chemoperception would allow a calanoid to perceive a food particle at a considerable distance (Andrews 1983). Thirdly, high speed/high resolution observations reveal that for nauplii of E. pileatus, the feeding current was directed towards 2 of the 3 pairs of cephalic appendages (Paffenhöfer \& Lewis 1989), and for copepodid stages and adult females of the same species toward 5 of their 6 pairs of cephalic appendages (Paffenhöfer \& Lewis 1990) and not towards the first antennae (A1). Similar observations were made for free-swimming adult females of Paracalanus aculeatus and Centropages velificatus (Bundy \& Paffenhöfer 1996). Moreover some freshwater copepods (the genus Diaptomus) can per- 
ceive, via mechanoreception, large particles (50 $\mu \mathrm{m}$ diameter) using their A1 (Bundy et al. 1998). Diatoms of diameter $11 \mu \mathrm{m}$ and larger cells were often perceived before they reached the tips of the setae of the various cephalic appendages, mainly maxilliped (Mxp) and second antennae (A2) (Paffenhöfer \& Lewis 1990). Since high sensitivity mechanoreception was unlikely to be performed by the flexible setae of the A2 and Mxp, we assumed that long distance perception of cells as small as $11 \mu \mathrm{m}$ would probably occur via chemoreception, as modeled by Andrews (1983). To investigate this further, we utilized Scanning (SEM) and Transmission Electron Microscopy (TEM). SEM was chosen to show whether the tips of setae of the mouthparts involved in perception, gathering and capture of food particles possessed an apical pore. Such pores are considered to be indicators of chemoreception capability (e.g. Schmidt \& Gnatzy 1984, Weatherby et al. 1994). TEM was chosen to identify ultrastructures indicative of mechano- and/ or chemosensors in various setae, as shown e.g. by Gill (1986), Kurbjeweit \& Buchholz (1991) and Weatherby et al. (1994) for setae of the A1 of several calanoid species.

To date, 4 studies on seta ultrastructure of cephalic appendages, other than the A1, have been conducted. Friedman \& Strickler (1975) described, from TEMs, structures of the mandibular palp of the freshwater copepod Diaptomus pallidus which were thought to represent chemosensors, but could not find features indicating mechanoreception. Second antennae and mandibles of nauplius Stage V of Eucalanus pileatus had structures indicative of both mechano- and chemoreception (Bundy \& Paffenhöfer 1997). Two types of setae of the Mxp of 2 species of mesopelagic copepods had structures which were thought to represent chemosensors (Nishida \& Ohtsuka 1997). All 16 setae of the maxilliped of the calanoid Temora stylifera had structures indicative of both mechano- and chemosensors (Paffenhöfer \& Loyd 1999).

Our overall intention is to describe and compare sensory structures on various cephalic appendages of several abundant copepod species in order to determine their sensory capabilities. Information on ultrastructures and their potential function was presented for setae of the Mxp of the calanoid copepod Temora stylifera by Paffenhöfer \& Loyd (1999). In the present study we examined the ultrastructure of setae of the A2 in the same species, because the A2, together with the Mxp, are the main cephalic appendages which perceive and displace incoming phytoplankton cells towards the mouth (e.g. Paffenhöfer \& Lewis 1990). Among the few available well-preserved appendage setae were those of the mandibular palp (MdP) of the copepod Centropages velificatus, which occasionally displaces particles towards the mouth (Paffenhöfer unpubl. data). Since apical pores of setae are considered one of the indicators of chemoreception, we compared setae of the Mxp of 4 different calanoid species for presence or absence of such pores.

\section{MATERIAL AND METHODS}

The 4 copepod species studied were adult females of calanoids which are found abundantly on the mid and outer shelf off the southeastern US (Bowman 1971) and in various subtropical and tropical regions around the world: Centropages velificatus, Eucalanus pileatus, Paracalanus aculeatus and Temora stylifera (e.g. Fleminger 1959, Fleminger \& Hülsemann 1973, Binet 1977, 1984, Valentin 1980, Madhupratap \& Haridas 1986, Sameoto 1986). Copepodid stages and females were collected regularly during spring, summer and autumn in oblique tows with a $200 \mu \mathrm{m}$ mesh net equipped with a 41 codend to minimize damage to the copepods' appendages, including setae. Copepodids were reared to females, which implied that the setae had not been damaged. The setae had hardly any particles adhering to them as compared to field-collected females which may have been quite old, and often had setae damaged and covered by particulate matter. We preserved several females of each of the 4 abovementioned species but successfully preserved the setae only in a very few specimens. Copepods were slowly anesthetized in a magnesium chloride solution $(3.5 \%)$ to prevent distortion of the cephalic appendages, and then processed in a similar way to the protocol established by Weatherby et al. (1994). Copepods were initially fixed for $30 \mathrm{~min}$ in $4 \%$ glutaraldehyde in $0.1 \mathrm{M}$ cacodylate buffer and $0.35 \mathrm{M}$ sucrose. The appendages were decalcified in $2 \%$ sodium EDTA for $30 \mathrm{~min}$, then placed for $30 \mathrm{~min}$ again in $4 \%$ glutaraldehyde in $0.1 \mathrm{M}$ sodium cacodylate, followed by 3 washings in $0.1 \mathrm{M}$ cacodylate. As soon as possible the copepods were postfixed for 60 min in $1 \%$ buffered osmium tetroxide, washed in $0.1 \mathrm{M}$ cacodylate, and then stepwise dehydrated from 30 to $100 \%$ ethanol. After this, we proceeded differently for SEM and TEM. The next steps for SEM were critical point drying, mounting of the copepods on stubs with silver paste, keeping them overnight in a desiccator, and finally sputter coating with gold. For TEM, we transferred the copepods to propylene oxide (PO), then to PO/EPON 812 and finally embedded them in EPON 812.

We obtained sections of $90 \mathrm{~nm}$ thickness with a Sorvall MT2-B ultramicrotome, and stained them with uranyl acetate followed by lead citrate. A LEO 982 Scanning Electron Microscope and a JEOL 100 CX Transmission Electron Microscope were utilized at the Laboratory for Advanced Ultrastructure Research at the University of Georgia, Athens, Georgia. 


\section{RESULTS}

\section{Scanning electron microscopy}

The maxillipeds (Mxp) of copepods that create feeding currents are frequently involved in the gathering of food particles, particularly phytoplankton cells (e.g. Price et al. 1983, Paffenhöfer \& Lewis 1990). To illustrate the location and morphology of a Mxp on a copepod, we present the cephalothorax with its appendages (Fig. 1a), a Mxp (Fig. 1b), and 2 setae with their apical pores (Fig. 1c,d) of an adult female of Centropages velificatus. In addition, apical pores of Mxp setae are shown for Temora stylifera (Fig. 2a), Eucalanus pileatus (Fig. 2b), and Paracalanus aculeatus (Fig. 2c). The setae which we could observe were inserted in the second, third or fourth segment from the Mxp tips and were among the longer ones of the respective segment. They measured between $\sim 2$ and $4 \mu \mathrm{m}$ in diameter at their base, and decreased to $0.5 \mu \mathrm{m}$ external diameter at their tip. Their lengths ranged from 75 to $160 \mu \mathrm{m}$ for $C$. velificatus, 70 to $380 \mu \mathrm{m}$ for E. pileatus, 30 to $160 \mu \mathrm{m}$ for $P$. aculeataus and 65 to $230 \mu \mathrm{m}$ for T. stylifera. Setae of the A2 of $P$. aculeatus also had apical pores (not shown).

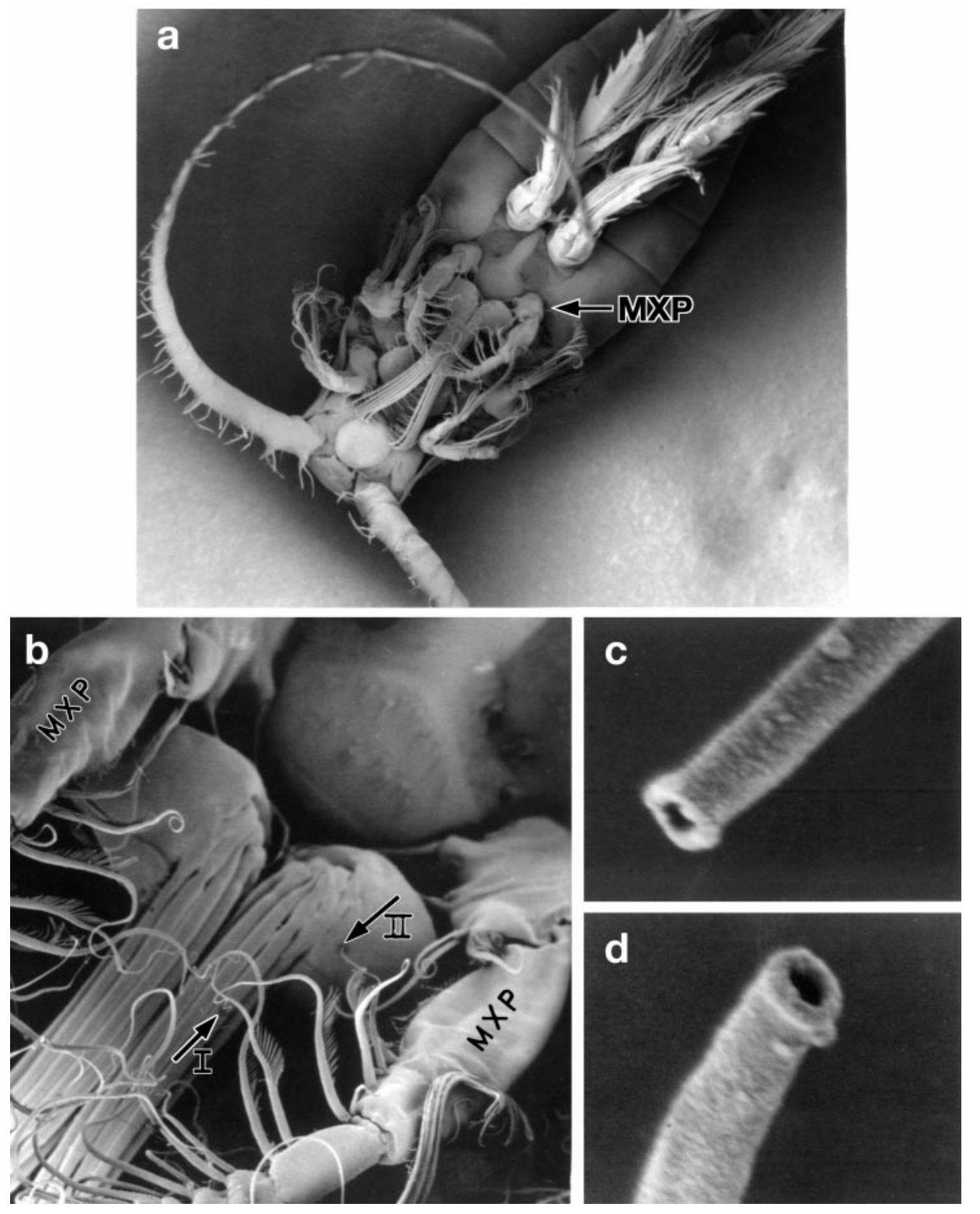

Fig. 1. Centropages velificatus, female. SEM. (a) Anterior of female, 78×, Mxp = maxilliped; (b) left Mxp, 390×, with arrows indicating 2 setae whose apical pores are presented in (c) at $75000 \times$, Seta I, and (d) $30000 \times$, Seta II 


\section{Transmission electron microscopy}

The structure of maxilliped setae of Temora stylifera was described in detail by Paffenhöfer \& Loyd (1999). Here we examined an A2 and also an MdP. The biramous A2 are largely responsible for creating the feeding current and gathering food particles (e.g. Paffenhöfer \& Lewis 1990), whereas the biramous MdP, which moves at the same frequency as the A2 and Mxp, has only occasionally been seen to actively gather cells (Paffenhöfer unpubl. obs.). We sectioned all except one of the 12 setae of the A2 exopod from distal to proximal (Figs. 3 \& 4). As pointed out by Ball \& Cowan (1977) for setae of the sergestid shrimp Acetes, preservation of ultrastructures in setae may be incomplete. We repeatedly experienced the same problem and therefore cannot present comprehensive information on all setae studied. We sectioned setae of 2 or 3 individuals of each species. Of the 12 exopod setae, 5 possessed structures indicative of mechano- and chemosensory function; another seta had only potential chemosensory, and another only mechanosensory structures; of the remaining 5 setae, no clear strucutres could be identified, mainly due to inadequate preservation. All of the above-mentioned 5, possibly dual-function, setae had 1 or 2 dendrites of putative mechanoperceptive, and 2 or more dendrites of putative chemopercep-

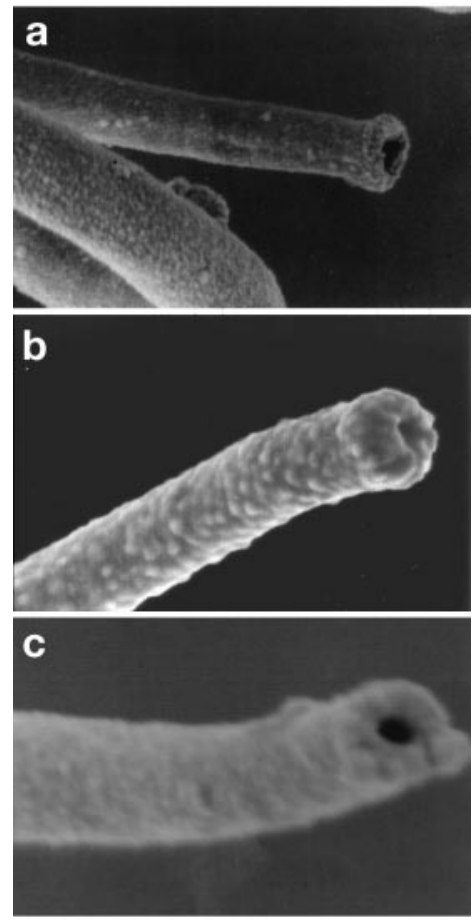

Fig. 2. SEM. Apical pores of maxilliped setae of adult females of (a) Eucalanus pileatus (20000×), (b) Paracalanus aculeatus $(50000 \times)$, and (c) Temora stylifera $(50000 \times)$ tive function. About $20 \mu \mathrm{m}$ from one seta's tip (one of the 4 setae of the segment closest to the basis) we observed a dendrite with 9 electron-dense bands at its periphery (Fig. 3a), suggesting a mechanoperceptive function (e.g. Weatherby et al. 1994). About $40 \mu \mathrm{m}$ further proximal, this dendrite (Fig. 3b) occupied most of the seta volume, and assumed the position of a $9+0$ cilium-like structure (pinwheel; 9 individual structures peripherally, no structure in the middle) about 110 to $130 \mu \mathrm{m}$ from the seta's tip (Fig. 3c,d). Here 2 dendrites are evident, each with translucent microtubules equally spaced and of putative chemosensory function. About $143 \mu \mathrm{m}$ from the tip, the pinwheel transformed to a circlet (Fig. 3e, e.g. Weatherby \& Lenz 1993), which is a structure very similar to a basal body which appears $\sim 2 \mu \mathrm{m}$ distal (Fig. 3f). The 3 dendrites are surrounded by a large enveloping cell. No distinct structures attributable to the inner dendritic segment could be identified. Concerning putative chemoperception, we observed 2 dendrites with equally spaced translucent microtubules $\sim 105 \mu \mathrm{m}$ from a seta's tip. This was one of the 4 setae on the exopod segment closest to the basis of the A2 (Fig. 4a). About $125 \mu \mathrm{m}$ from the tip, these 2 dendrites occupied most of the seta's volume and began to form microtubule doublets (Fig. 4b). About $145 \mu \mathrm{m}$ from the tip, 1 of the 2 dendrites now had 9 doublets with several single microtubules left. The 2 dendrites were accompanied by a third dendrite and an enveloping cell, both containing translucent microtubules positioned at various distances from each other (Fig. 4c). At $4 \mu \mathrm{m}$ distally the respective dendrite now has a cilium-like structure of $9 \times 2+0$ ( 9 individual structures peripherally, each consisting of 2 (joint) microtubules, and no structure in the middle) (Fig. 4d) which $0.4 \mu \mathrm{m}$ farther proximal has become a basal body (Fig. 4e). Here the enveloping cells are clearly visible.

Of the 10 setae of the endopod of the mandibular palp of a female Centropages velificatus, 9 were well preserved; of the 9, 7 had potential dual function (Fig. 5), and the other 2 had only structures indicative of chemoperceptive function. We always found only 1 mechanoperception dendrite (putative), and usually 2 or more dendrites per seta with translucent microtubules (putative chemoperception). Of the latter, only 2 had equally spaced translucent microtubules which could develop into basal bodies (e.g. Fig. 5f). Of the 6 setae of the exopod of the mandibular palp, 5 had putative mechanoperception structures (1 dendrite per seta), and the remaining 1 had only putative chemoperception strucutres; of the former 5, 4 had translucent microtubules (chemoperception, 1 dendrite per seta), i.e. seemed to be of potential dual function. The setae of potential dual function as shown for the endopod (Fig. 5) ranged in length from 120 to $270 \mu \mathrm{m}$. About $40 \mu \mathrm{m}$ from a seta's tip we observed 3 dendrites con- 

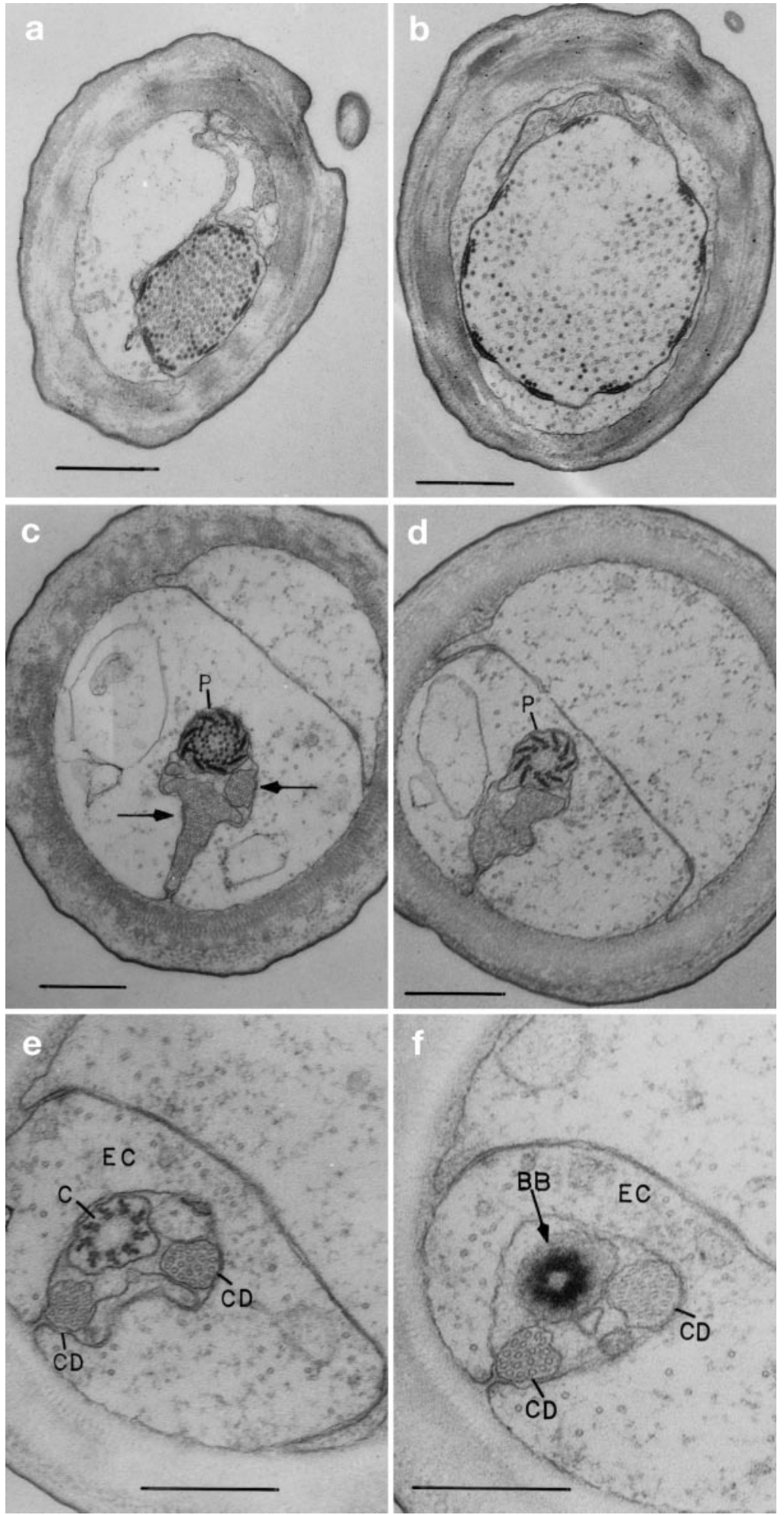

Fig. 3. Temora stylifera, female. Second antenna, exopod. TEM cross-sections showing structures associated with a putative mechanosensory dendrite. (a) One dendrite with 9 electron-dense bands at its periphery, $30 \mu \mathrm{m}$ from the seta's tip; (b) same dendrite has widened, $\sim 70 \mu \mathrm{m}$ from tip; (c) same dendrite has formed a 9-spoke pinwheel (P); nearby are 2 dendrites with translucent microbules (arrows), $\sim 110 \mu \mathrm{m}$ from tip; (d) same structures, now $\sim 130 \mu \mathrm{m}$ from tip; (e) pinwheel transformed to a circlet (C), $\sim 143 \mu \mathrm{m}$ from tip, which at (f) becomes a basal body (BB), 145 $\mu \mathrm{m}$ from tip; both (e) and (f) show putative chemosensory dendrites $(\mathrm{CD})$ and enveloping cell $(\mathrm{EC})$; scale bars $=0.5 \mu \mathrm{m}$ 

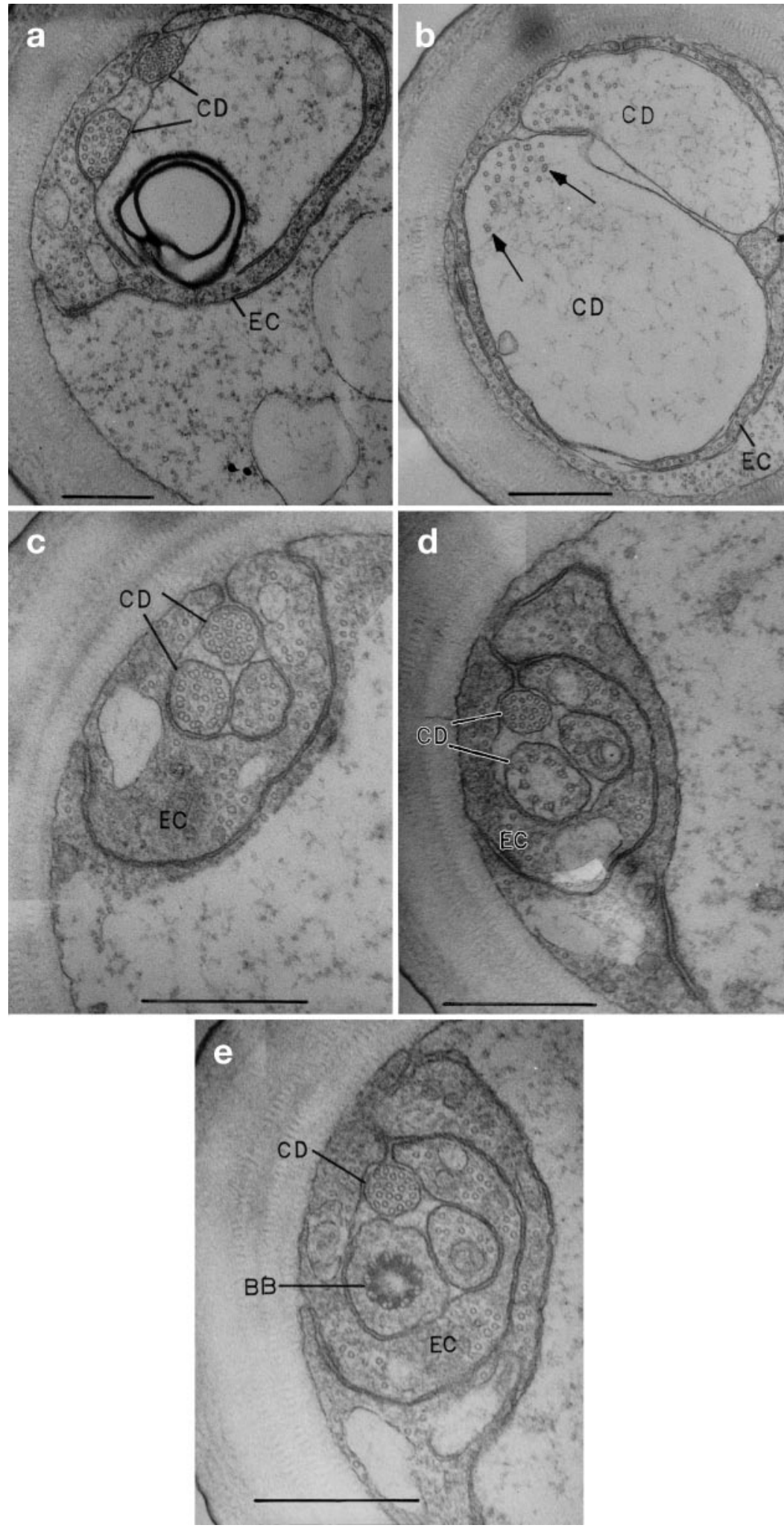

Fig. 4. Temora stylifera, female. Second antenna, exopod. TEM of structures indicative of chemosensory dendrites. (a) Two dendrites (CD) with translucent microtubules and one enveloping cell (EC) in the middle part of the seta, 105 $\mu \mathrm{m}$ from its tip; (b) further proximal, $\sim 125 \mu \mathrm{m}$ from the tip, doublets indicated by arrows; (c) more proximal, $\sim 145$ from tip; (d) $\sim 149 \mu \mathrm{m}$ from tip; (e) putative chemosensory basal body (BB) $\sim 0.4 \mu \mathrm{m}$ proximal from (d); scale bars $=0.5 \mu \mathrm{m}$ 

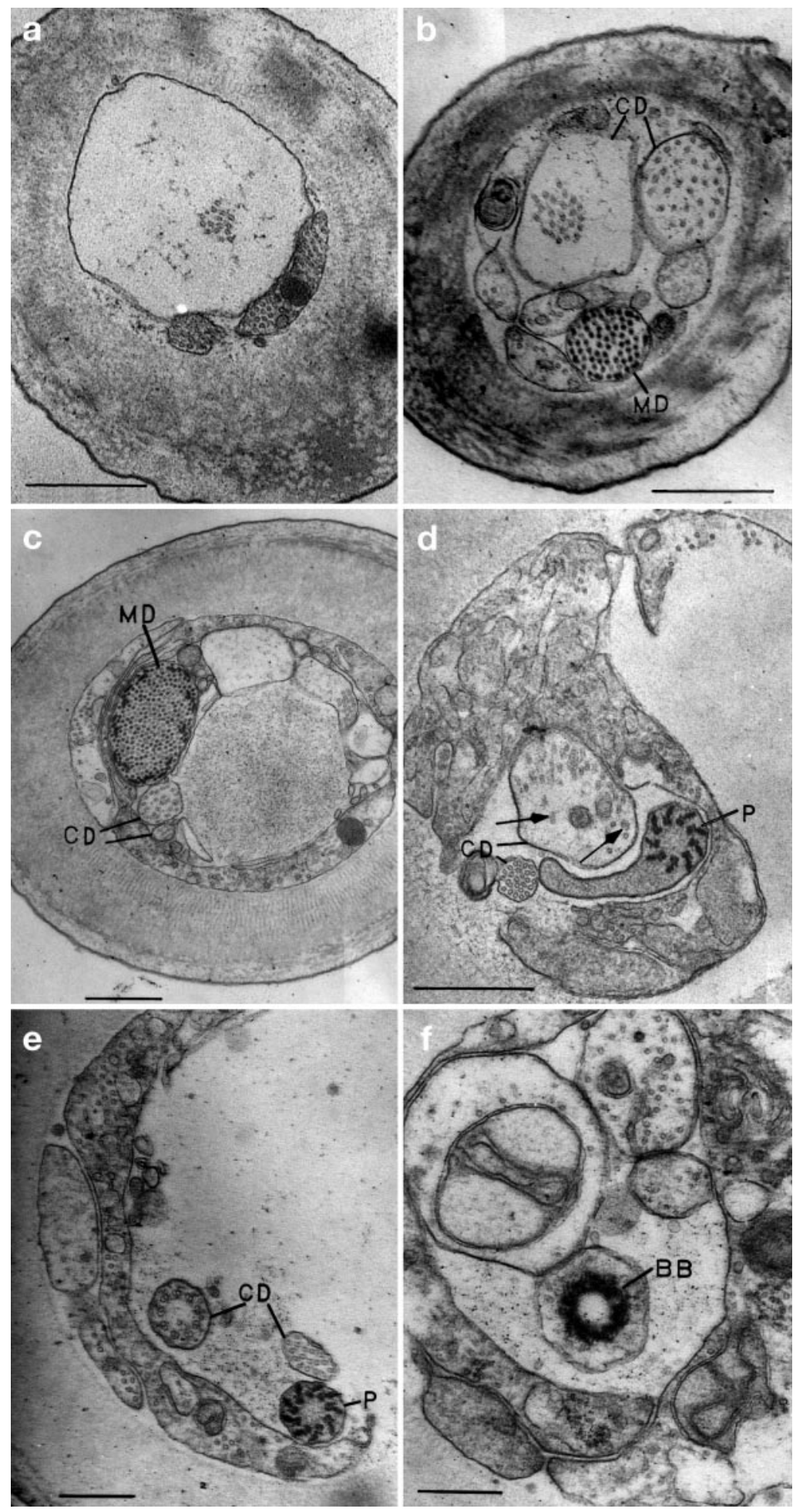

Fig. 5. Centropages velificatus, female. Mandibular palp, endopod. TEM of structures indicative of mechano- and chemosensory dendrites. (a) Three dendrites, $\sim 40 \mu \mathrm{m}$ from tip of seta; (b) 2 dendrites with translucent (CD), and one with electron-dense microtubules (MD), $\sim 80 \mu \mathrm{m}$ from tip; (c) one mechanosensory dendrite (MD) with 9 electron-dense bands at its periphery, 2 dendrites with translucent microtubules (CD); (d) pinwheel (P) and 2 dendrites with translucent microtubules of which one shows the beginning of the formation of doublets (arrows), $125 \mu \mathrm{m}$ from seta tip; (e) pinwheel, 2 dendrites (CD) of which one has developed a $9 \times 2$ formation, $\sim 137 \mu \mathrm{m}$ from tip; (f) the $9 \times 2$ structure has developed $\sim 25 \mu \mathrm{m}$ farther proximal into a basal body (BB) of assumed chemosensory function; the inner dendrite segment of the mechanosensory dendrite could not be found; scale bars $=0.5 \mu \mathrm{m}$ 
taining translucent microtubules positioned at quite even intervals (Fig. 5a). Close to $50 \mu \mathrm{m}$ proximal 2 dendrites possessed translucent and 1 dendrite electrondense microtubules (Fig. 5b) which at $15 \mu \mathrm{m}$ more proximal had formed 9 peripheral bands (Fig. 5c). Two dendrites with fairly evenly spaced translucent microtubules remained. About $125 \mu \mathrm{m}$ from the seta's tip the microtubules of both of these 2 dendrites had begun to form doublets and the peripheral bands had turned into a cilium-like structure, i.e. a pinwheel (Fig. 5d). Several microns farther proximal, the pinwheel persisted and 1 of the 2 other dendrites had formed a different cilium-like structure, i.e. $9 \times 2$ translucent microtubules (Fig. 5e) which about $20 \mu \mathrm{m}$ proximal formed a basal body (Fig. 5f).

None of the previous mechanosensory structures was surrounded by a scolopale which had been observed surrounding mechanosensory dendrites in single function and dual function/bimodal setae on the A1 of the planktonic copepod Pleuromamma xiphias (Weatherby \& Lenz 1995). We cross-sectioned setae on the distal segment of the A1 of a copepodid stage IV of Eucalanus pileatus and repeatedly found mechanosensory dendrites surrounded by a distinct scolopale (not shown).

\section{DISCUSSION}

\section{Morphology and anatomy of setae}

Our goal was to compare the ultrastructures of several marine planktonic copepods for evidence of structures indicative of mechano- and/or chemosensory function. All the setae of the maxillipeds of the 4 calanoid species that were in a position after fixation to have their tips inspected possessed an apical pore (Figs. 1 \& 2). We did not inspect setae of other appendages except those of the A2 of Paracalanus aculeatus, which also had apical pores (not shown). These observations are in agreement with the description of an apical pore of a seta of the Mxp of a Temora stylifera female using TEM (Paffenhöfer \& Loyd 1999). Our TEM observations of cross-sections of setae of the A2 of T. stylifera (Figs. 3 \& 4) and the MdP of Centropages velificatus (Fig. 5) revealed that the majority of setae had ultrastructures resembling those found for all setae of the Mxp of T. stylifera, i.e. at least 1 dendrite with 9 electron-dense peripheral bands developing proximally from a 9 -spoke pinwheel into a 9-strand circlet $(9+0$ cilium) and finally into an electron-dense basal body (e.g. Fig. 3); and usually 2 dendrites with evenly spaced translucent microtubules which proximally formed doublets, and which then formed a circle of $9(9 \times 2$ configuration), and more proximal became a basal body with the 9 doublets connected by electrondense material (Figs. 3f, 4e \& 5f). The electron-dense basal body with its dendrite is considered to be of mechanosensory function (Weatherby \& Lenz 1993, Weatherby et al. 1994), and the $9 \times 2$ basal body (translucent doublets) of chemosensory function (Paffenhöfer \& Loyd 1999). The latter basal body closely resembled those of the Type II dendrites $(9 \times 3$ translucent +0 ) of the crab Carcinus maenas (Schmidt \& Gnatzy 1984) which these authors thought had chemosensory capabilities. Zacharuk (1985) described a similar basal body $(9 \times 3+0)$ for a chordotonal sensillum in antennae of larvae of the yellow mealworm Tenebrio molitor but did not attribute to it any specific function. A structure described by Weatherby et al. (1994) and a chemoreceptive dendrite in a dual function seta of the A1 of Pleuromamma xiphias (their Fig. 7e) appeared to be quite similar to our $9 \times 2$ basal bodies. The presence of 1 apical pore per observed seta and the 2 different types of dendrites make it possible that some, if not most, setae on the A2, Mdp and Mxp of the 4 studied copepod species are of dual/bimodal function.

None of the dendrites of assumed mechanosensory function in this study, as well as in the Mxp of Temora stylifera (Paffenhöfer \& Loyd 1999) were surrounded by a scolopale as observed e.g. by Weatherby et al. (1994) in setae of the A1 of mechanosensory and dual function. We also found scolopales surrounding pairs of pinwheels in a seta of the outermost segment of the A1 of a copepodite of Eucalanus pileatus (not shown). The scolopale on many of the A1 setae provides stiffness which the setae of the A2, MdP and Mxp so far observed in high-speed films of these 4 copepod species do not possess. They can bend in different directions depending on appendage motion. Both types of seta possess different functions as described below.

\section{Function}

Copepodid stages and adult females of the 4 copepod species studied create a feeding current which almost continuously displaces water towards and past the individual. The cephalic appendages mainly contributing to this water motion are the A2 and the Mxp which, together with the MdP and first maxillae (M1), move at frequencies between $\sim 25 \mathrm{~Hz}$ (Eucalanus pileatus) and $\sim 80 \mathrm{~Hz}$ (Paracalanus aculeatus). Thus, a parcel of the feeding current water, which has a velocity between $\sim 4$ and $\sim 8 \mathrm{~mm} \mathrm{~s}^{-1}$ near the copepods' appendages, is scanned about 6 and 3 times, respectively, by the setae of the Mxp and A2 of a $P$. aculeatus female, and $\sim 3.7$ and 1.8 times, respectively, by the Mxp and A2 setae of a female of E. pileatus as it passes 
from anterio-ventral to posterio-dorsal of the copepod. This implies that the setae pass repeatedly through much of the displaced water. The tips of the setae, carrying the apical pores, cover the greatest distance and presumably scan a larger volume of water than any other parts of the appendage. Therefore, the probability is quite high that individual molecules of organic chemical compounds, which surround or even precede the food particle from which they had been exuded, could encounter apical pores and be perceived (Andrews 1983). Previous observations (e.g. Paffenhöfer \& Lewis 1990) had shown that E. pileatus reacted to oncoming food particles of $11 \mu \mathrm{m}$ diameter and larger prior to them reaching the moving setae of the Mxp and A2. This led to the assumption that chemoperception was involved, since mechanoperception of an $11 \mu \mathrm{m}$ particle by a flexible seta was unlikely. However, it is commonly thought that setae with an apical pore have a gustatory function (e.g. Zacharuk 1980, Lenz et al. 1996), requiring contact with the apical pore and time-consuming access of molecules to the respective dendrites. Zacharuk (1980) mentioned the occurrence of dense exudates at the tips of uniporous setae of insects, and we observed a fluffy substance in the outlet of a pore of a Mxp seta of Temora stylifera (Paffenhöfer \& Loyd 1999). We hypothesize that speedy uptake of a respective food particle molecule by an odorant-binding protein could result in an ion exchange (Zacharuk 1985) that produces a signal which could be rapidly transmitted by microtubules which end near the pore (Paffenhöfer \& Loyd 1999) towards an axon, and result in a signal to gather the oncoming particle within its surrounding body of water. These hypothetical processes currently seem to be the most probable interpretations of our ultrastructure and cinematographic-video observations, and require physiological verification. Our hypotheses imply that a so-called gustatory process, i.e. molecule 'capture' by molecule-binding proteins at the pore tip, would be, in reality, an olfactory process, since the molecule-releasing particle is at a certain distance from the perceiving and gathering appendage. Gustation occurs at the copepod's mouth as described earlier (Paffenhöfer et al. 1982).

We presume that the function of the mechanosensory structures in the setae of A2, MdP and Mxp is different from that of the rigid structures of setae observed on the A1 of Pleuromamma xiphias (Weatherby et al. 1994). The setae we observed were bending as they moved back and forth creating the feeding current. Although the thickness of the cuticula (e.g. of setae of Mxp of Temora stylifera near the tip, $\sim 0.09 \mu \mathrm{m}$, and near insertion into the appendage, $\sim 0.9 \mu \mathrm{m}$ ) did not differ much from that of setae at the tip of the A1 of P. xiphias (Weatherby et al. 1994), the absence of scolopales around mechanosensory dendrites was at least partly the cause for the observed bending. Yet these mechanosensory-like structures must have a task to fulfill. We assume, as mentioned earlier (Paffenhöfer \& Loyd 1999), that they participate in the gathering and rejection processes of individual food particles.

\section{CONCLUSION}

All the setae observed by SEM in this study possessed an apical pore (Mxp, A2). Most of the setae cross-sectioned had ultrastructures indicative of mechano- and chemosensory function (A2 of Temora stylifera and MdP of Centropages velificatus) as observed earlier for all setae of the Mxp of T. stylifera (Paffenhöfer \& Loyd 1999). Most of the setae of the A1 of the calanoid copepod Pleuromamma xiphias had bimodal/dual function (Lenz et al. 1996). Insect sensilla which have a pore at or near the tip (uniporous) look like hairs and have a dual function, i.e. mechano- and chemoperception (Zacharuk 1985). Dual function of sensilla is common not only among insects, but also among crustaceans (e.g. Altner et al. 1983, Schmidt \& Gnatzy 1984). Our observations reveal a similar dual function. However, the function of sensors on copepods' appendages such as the A2, MdP and Mxp seems to differ, at least partly, from those described previously for setae of the A1. We assume that these rapidly moving appendage setae function in conjunction with the feeding current water by scanning it continuously and frequently. These setae cover most of the extending Mxp (Fig. 1a) and are positioned like fans on the exo- and endopod of the A2. This results in a high probability of the setae tips encountering and 'capturing' molecules originating from and preceding a food particle, which leads to transmission of a signal that triggers the gathering of the food particle. A premise of our hypothesis is that the process of molecule capture with ensuing transmission of signals is rapid, i.e. in the order of $0.1 \mathrm{~s}$. The non-moving A1 setae usually perceive signals further away from the copepod. These signals are often hydrodynamic, i.e. from predators or prey, but could also be chemical (e.g. Bundy \& Paffenhöfer 1993, Weatherby et al. 1994). Many of the A1 sensors are outside the range of the copepod's feeding current and encounter only the water moving around them at the speed of the slowly swimming copepod (usually $\sim 0.5$ to $1 \mathrm{~mm} \mathrm{~s}^{-1}$ ). In essence, our observations indicate that for copepodid stages and adult females with feeding currents there appears to be a clear difference in sensory performance and function of setae of the A1 as compared to those of the A2, MdP and Mxp. 
Acknowledgements. Our studies were supported by a grant from the National Science Foundation (OCE 94 15791). Tina Weatherby Carvalho (University of Hawaii at Manoa), Cathy Kelloes, Mark Farmer and John Shields (University of Georgia) made these studies possible with valuable advice and guidance. The Center for Advanced Ultrastructure Research at the University of Georgia (Dr Mark Farmer) provided the Scanning and Transmission Electron Microscopes, and the Marine Extension Service of the University of Georgia the ultramicrotome. Their support is gratefully acknowledged.

\section{LITERATURE CITED}

Altner I, Hatt H, Altner H (1983) Structural properties of bimodal chemo- and mechanosensitive setae on the pereiopod chelae of the crayfish Austropotamobius torrentium. Cell Tissue Res 228:357-374

Andrews JC (1983) Deformation of the active space in the low Reynolds number feeding current of calanoid copepods. Can J Fish Aquat Sci 40:1293-1302

Ball EE, Cowan AN (1977) Ultrastructure of the antennal sensilla of Acetes (Crustacea, Decapoda, Natantia, Sergestidae). Proc R Soc (Lond) B 277:429-457

Binet D (1977) Cycles biologiques et migrations ontogenetiques chez quelques copepodes pelagiques des eaux ivoiriennes. Cah ORSTROM Ser Oceanogr 15:111-138

Binet D (1984) Copepodes planctoniques du lagon de Nouvelle-Caledonie: facteurs ecologiques et associations d'especes. Mar Biol 82:143-156

Bowman TE (1971) The distribution of calanoid copepods off the Southeastern United States between Cape Hatteras and Southern Florida. Smithson Contr Zool 96

Bundy MH, Paffenhöfer GA (1993) Innervation of copepod antennules investigated using laser scanning confocal microscopy. Mar Ecol Prog Ser 102:1-14

Bundy MH, Paffenhöfer GA (1996) Analysis of flow fields associated with freely swimming calanoid copepods. Mar Ecol Prog Ser 133:99-113

Bundy MH, Paffenhöfer GA (1997) The innervation of the setae on the appendages of the nauplius of Eucalanus pileatus Giesbrecht. Mar Fresh Behav Physiol 30:195-207

Bundy MH, Gross TF, Vanderploeg HA, Strickler JR (1998) Perception of inert particles by calanoid copepods: behavioral observations and numerical model. J Plankton Res 20:2129-2152

Fleminger A (1959) Distribution of calanoid copepods in the Gulf of Mexico. In: Sears M (ed) International Oceanographic Congress. Am Assoc Adv Sci, New York, p 153-154 (preprint)

Fleminger A, Hülsemann K (1973) Relationship of Indian Ocean epiplanktonic calanoids to the World Oceans. In: Zeitzschel B (ed) The biology of the Indian Ocean. Springer-Verlag, New York, p 339-347

Friedman MM, Strickler JR (1975) Chemoreceptors and feeding in calanoid copepods (Arthropoda: Crustacea). Proc Natl Acad Sci USA 72:4185-4188

Gill CW (1986) Suspected mechano- and chemosensory structures of Temora longicoruis (Copepoda: Calanoida). Mar Biol 93:449-457

Kurbjeweit F, Buchholz C (1991) Structures and suspected functions of antennular sensilla and pores of three Arctic copepods (Calanus glacialis, Metridia longa, Pareuchaeta norvegica). Meeresforschung 33:168-182

Lenz PH, Weatherby TM, Weber W, Wong KK (1996) Sensory

Editorial responsibility: Jennifer Purcell (Contributing Editor), Cambridge, Maryland, USA specialization along the first antenna of a calanoid copepod, Pleuromamma xiphias (Crustacea). Mar Fresh Behav Physiol 27:355-363

Madhupratap M, Haridas P (1986) Epipelagic calanoid copepods in the northern Indian Ocean. Oceanol Acta 9: $105-117$

Nishida S, Ohtsuka S (1997) Ultrastructure of the mouthpart sensory setae in mesopelagic copepods of the family Scolecitrichidae. Plankton Biol Ecol 44:81-90

Paffenhöfer GA, Lewis KD (1989) Feeding behavior of nauplii of the genus Eucalanus (Copepoda, Calanoida). Mar Ecol Prog Ser 57:129-136

Paffenhöfer GA, Lewis KD (1990) Perceptive performance and feeding behavior of calanoid copepods. J Plankton Res 12:933-946

Paffenhöfer GA, Loyd PA (1999) Ultrastructure of setae of the maxilliped of the marine planktonic copepod Temora stylifera Dana. Mar Ecol Prog Ser 178:101-107

Paffenhöfer GA, Strickler JR, Alcaraz M (1982) Suspensionfeeding by herbivorous calanoid copepods: a cinematographic study. Mar Biol 67:193-199

Price HJ, Paffenhöfer GA, Strickler JR (1983) Modes of cell capture in calanoid copepods. Limnol Oceanogr 28: $116-123$

Sameoto DD (1986) Influence of the biological and physical environment on the vertical distribution of mesozooplankton and micronekton in the eastern tropical Pacific. Mar Biol 93:263-279

Schmidt M, Gnatzy W (1984) Are the funnel-canal organs the 'campaniform sensilla' of the shore crab, Carcinus maenas (Decapoda, Crustacea)? II. Ultrastructure. Cell Tissue Res 237:81-93

Strickler JR (1984) Sticky water: a selective force in copepods evolution. In: Meyers DG, Strickler JR (eds) Trophic interactions within aquatic ecosystems. AAAS Selected Symposium 85, Westview Press, Boulder, CO, p 187-239

Strickler JR (1985) Feeding currents in calanoid copepods: two new hypotheses. In: Laverack MS (ed) Symposia of the Society of Experimental Biology, No. 39; Physiological adaptation of marine animals. The Company of Biologists Ltd, Cambridge, p 455-485

Valentin J (1980) L'ecosysteme d'upwelling à Cabo Frio (Bresil) Analyse en composantes principales du plancton à une station fixe. Oceanol Acta 3:43-50

Weatherby TM, Lenz PH (1993) Proliferation of microtubules from discrete electron-dense bodies in the ciliary dendritic portion of mechanosensory setae of copepod antennae. In: Bailey GW, Rieder CL (eds) Proc 51st Annual Meeting Microscopy Soc America. San Francisco Press, San Francisco, p 340-341

Weatherby TM, Lenz PH (1995) Ultrastructure identification of three types of sensory setae on copepod antennae. In: Bailey GW, Ellisman MH, Hennigar RA, Zaluzec NJ (eds) Proc Microscopy and Microanalysis. Jones \& Begell Publ, New York, p 956-957

Weatherby TM, Wong KK, Lenz PH (1994) Fine structure of the distal sensor setae on the first antennae of Pleuromamma xiphias Giesbrecht (Copepoda). J Crustac Biol 14: $670-685$

Zacharuk RY (1980) Ultrastructure and function of insect chemosensilla. Annu Rev Entomol 25:27-47

Zacharuk RY (1985) Antennae and sensilla. In: Kerkut G, Gilbert L (eds) Comprehensive insect physiology, biochemistry and pharmacology, Vol 6. Pergamon Press, Oxford, p 1-69

Submitted: April 7, 1999; Accepted: October 21, 1999

Proofs received from author(s): August 9, 2000 